\title{
A Narrativa Radiofônica como estratégia de formação docente no Projeto UCA
}

\author{
Autor: Marciel A. Consani \\ Instituições: (1) Instituto de Artes-UNICAMP (Campinas/SP) \\ (2) Centro de Comunicação e Artes-ECA/USP (Cidade Universitária-São Paulo/SP) \\ Contato principal: $\underline{\text { mconsani@usp.br }}$ \\ (e-mail alternativo: marcielc@gmail.com )
}

\begin{abstract}
Resumo
Este artigo trata de uma aplicação vivencial de mídia na Educação. A linguagem trabalhada é a do rádio num contexto de formação docente em uma escola pública de Campinas (SP). Dois grupos de professores participam de uma série de três encontros que se propõem, a partir do eixo articulador da Narrativa, a construir uma dinâmica que os estimule a desenvolver projetos educativos incluindo a tecnologia digital de áudio presente na plataforma XO do Projeto UCA. A aplicação encontra-se ainda em curso, mas a receptividade da proposta, bem como o retrospecto de iniciativas semelhantes, apontam para a obtenção de resultados animadores dentro da dinâmica do UCA.
\end{abstract}

Palavras-chave: Narrativa, radio, áudio digital, Letramento Midiático, formação docente.

\begin{abstract}
The present article is about an experiential application of media in education. The Radio appears as a language in a teacher-training context in a public school in Campinas (SP). Two groups of teachers participate in a three meetings using the narrative as an axis to develop educational projects with the digital audio resources of Project UCA XO platform. The application is still in progress, but the responsiveness of the proposal, as well as what was observed in similar experiments indicate encouraging results within this kind of work applied in UCA Project.
\end{abstract}

Keywords: Narrative, radio, digital audio, Media Literacy, teach training. 


\section{Introdução}

A Educação para as Mídias no Brasil e em outros países, sempre foi uma atividade condicionada a múltiplas diretrizes. Em nosso caso, embora não possamos dizer que tais diretrizes sejam unificadas pedagógica ou didaticamente, talvez seja possível identificar duas linhas básicas de abordagem, historicamente constituídas:

1. o uso das mídias (sem aprofundamento das respectivas linguagens) como uma tarefa correlata à da informatização das escolas;

2. a incorporação das tecnologias digitais em atividades educativas desenvolvidas com base nas linguagens comunicacionais.

Por um lado, seria tentador inferir que a divisão entre as duas orientações seja claramente delimitada em todos os casos, mas o que se observa, no universo das escolas e instituições educativas, é um largo espectro de orientações dos mais diversos matizes. Por outro lado, esta divisão de base histórica que mencionamos aqui tende a se diluir por efeito da convergência crescente entre as demandas da área e das próprias tecnologias que lhes dão suporte.

É sob esta perspectiva que trataremos aqui de uma vivência em formação docente dentro do Projeto Um Computador por Aluno (UCA), a qual teve lugar na EMEF Elza Maria Pellegrini de Aguiar, no município de Campinas (SP).

Neste ponto, caberia uma breve apresentação pessoal: sou educador desde 1989, tendo iniciado nesta carreira atuando estritamente no campo das Artes. Foi justamente este trabalho o que me levou à área de produção gráfica e audiovisual e, em consequência, à apropriação das tecnologias digitais envolvidas nestas tarefas. Tenho me dedicado, nos últimos de anos, ao capítulo da formação docente para o uso da Mídia na escola, em projetos de interação presencial e também a distância.

Os vários contextos nos quais atuei, nos últimos anos, me permitiram o contato com referenciais muito diversos, que incluem a Informática Educativa, a Literacia Digital (aportuguesamento de Media Literacy) e a Educomunicação [Soares, 2012].

No meu contato frequente com educadores, na qualidade de formador, sempre tive a impressão de esbarrar, cedo ou tarde, num limite que demarcava uma queda ou mesmo uma quebra na curva de aprendizado dos participantes.

$\mathrm{Na}$ verdade, a problemática toda envolveria várias abordagens, incluindo variáveis como a distância do formador (enquanto "especialista") em relação ao formando, ou a barreira do conhecimento "técnico" (tecnológico, mais precisamente) dificultando a apropriação das Mídias e tecnologias por parte dos professores. Aprofundar aqui estes temas, no entanto, demandaria um volume de texto, fora do âmbito e do foco deste breve workshop.

Assim, vamos abreviar os prolegômenos afirmando que, na minha perspectiva, concluí pela necessidade de encontrar um denominador comum que funcionasse como 
eixo articulador de conhecimentos para todos os contextos - ou, pelo menos, para a maioria deles.

Daí se originou a ideia de trabalhar com o conceito "guarda-chuva" de Narrativa e seus múltiplos desdobramentos. É claro que outros fatores importantes influíram nesta escolha especifico como meu direcionamento acadêmico para o campo da Comunicação e a minha adesão, há pouco mais de um ano, a um grupo de pesquisa dedicado especificamente ao estudo das Novas Narrativas.

O passo seguinte foi relativamente simples: o de alinhar meu Projeto de Pesquisa em nível de Pós-doutoramento, o qual já se aproveitava o meu background de formador docente, centralizando meu viés de pesquisa sobre o uso das Narrativas no Letramento Digital e Midiático dos professores.

A proposta de workshop aqui apresentada, de certa forma sintetiza este esforço para integrar a Mídia na prática educativa da escola pública, incorporando a expertise que pude desenvolver ao longo destes anos, e evitando incorrer em qualquer resquício da didática instrucionista, entendida como aquela centrada na instrumentalização dos professores.

A aplicação propriamente dita desta estratégia, bem como a sistematização dos resultados, está em andamento, mas as considerações aqui expostas se beneficiam de vários anos de prática formativa e de pesquisa correlata no contexto da escola pública.

\section{Da Narrativa Radiofônica}

\subsection{O que chamamos aqui de "Narrativa"?}

Dado o grande número de acepções que este termo assume, cabe aqui delimitar o sentido específico que ele assumirá em nosso texto. Esta primeira tarefa não é fácil, nem isenta de risco, não pela falta, mas pelo excesso de referenciais aportados das áreas que conhecimento que se apropriam do conceito de Narrativa. Só para fazer uma simples alusão, poderíamos, de passagem, mencionar, dentro das Ciências Humanas e Sociais, a literatura, a linguística, a antropologia, a história e a sociologia; no campo das Artes, o teatro, a música e a dança e no da Comunicação, o audiovisual (incluindo o cinema e o rádio) e o jornalismo.

Assim, nos permitiremos uma delimitação sincrética, baseada em pontos essenciais e, de certa forma, unívocos, compartilhados pelas diversas vertentes mencionadas no parágrafo anterior.

Em primeiro lugar, podemos considerar que a Narrativa é o ato ou processo de se narrar uma história - entendida como uma sucessão de eventos conectados numa relação causaefeito. Neste sentido, a expressão "narrativa" não pode ser utilizada como um sinônimo de história, visto que esta última se aplica ao conteúdo narrado ou objeto do narrar.

Se desenvolvermos nossa concepção partindo desta premissa, podemos dizer que uma narrativa apresenta características bem nítidas, como por exemplo: 
a. Unidade Informacional, ou seja, a já citada organização lógica e causal dos eventos narrados.

b. Configuração do processo narrado em etapas (ou seções) reconhecíveis como "começo/meio/fim". Aqui encontramos a sucessão usual da "curva dramática" (termo aportado das artes cênicas), pautada na apresentação, desenvolvimento e resolução de uma ação.

c. Intencionalidade Comunicativa, que se relaciona com a transmissão de um conteúdo específico que visa a transformação de um ou mais aspectos pertinentes ao ouvinte.

d. Desenvolvimento dinâmico do processo narrativo, entendido como sua constituição em tempo real, no momento em que se narra.

Também seria interessante estabelecer que o uso da narrativa na educação, em si, nada tem de novo, e que a razão de ser de nossa proposta se apoia em dois pontos: (1) no uso da mídia rádio em formato digital e (2) na sistematização deste uso com base nos recursos da plataforma XO.

\subsection{Por que o Rádio?}

Mencionar o uso do rádio na educação pode evocar a memória de projetos de Educação a Distância de Segunda Geração [Moore \& Kearsley, 2007], limitados ao formato de lições transmitidas em horários pré-determinados e desprovidas de interatividade.

Este modelo, cujas potencialidades foram amplamente esgotadas e superadas ainda em meados do século XX, não pode ser entendido como o "estado de arte" no uso da radiofonia na educação nos dias de hoje.

$\mathrm{Na}$ verdade, a abordagem da Educação Midiática [Buckingham 2003] muda o foco do trabalho educativo da recepção para a produção de conteúdos, deslocando o "ouvinte" de sua condição, tradicionalmente passiva, para a de protagonista. Assim, as características que se associam à linguagem radiofônica, como o baixo custo de produção, interface simples, familiaridade e expressão oral (oralidade), o convertem em um poderoso recurso nas situações de ensino-aprendizagem.

Dessas características comunicacionais do rádio, a oralidade talvez seja a que mais o aproxima do contexto educacional [Consani 2007]. Mesmo o uso intenso da escrita na educação, durante séculos, não diminuiu o impacto da comunicação oral dentro da escola e o advento da tecnologia digital ampliou ainda mais a gama de recursos pertinentes à linguagem.

No contexto particular da formação docente, a atividade de contar histórias sempre esteve presente, desde as séries iniciais, adquirindo grande importância na aquisição da leitura ou do letramento alfabético. 
Já o emprego do rádio pode agregar vantagens adicionais, tais como o desenvolvimento das competências comunicativas aliando escrita e fala, a motivação provocada pelo compartilhamento de repertório cultural entre os participantes, o estímulo provocado pelo prazer da atividade criativa e a ampliação da gama de recursos à disposição do professor de virtualmente qualquer disciplina.

Do lado da escola, podemos ainda enumerar (a) a flexibilização do paradigma disciplinar, viabilizando a construção de projetos educativos inter e transdisciplinares; (b) a construção e fortalecimento de vínculos culturais dentro do grupo docente e deste com comunidade do entorno (socialização cooperativa/colaborativa) e (c) o exercício da análise crítica frente às narrativas midiáticas (leitura crítica da mídia).

Mesmo disponde de uma boa base conceitual e empírica, restava ainda o desafio de propor uma estratégia formativa adequada para a demanda da unidade escolar envolvida no processo. Isto equivale a postular a necessidade permanente de modelar a formação às características idiossincráticas da escola, ao invés de buscar enquadrá-la dentro dos moldes de uma metodologia previamente determinada.

\section{Criando uma estratégia vivencial na escola}

\subsection{Do contexto}

A EMEF Elza Maria Pellegrini de Aguiar faz parte do grupo de escolas assessorada técnica e pedagogicamente pelo NIED (Núcleo de Informática Aplicada à Educação da Unicamp) no desenvolvimento do Projeto UCA (Um Computador por Aluno). Ela se encontra numa localização periférica no município de Campinas e atende cerca de oitocentos alunos na faixa etária que vai dos oito aos dezesseis anos.

Nunca é demais recordar que o "Uquinha", como apelidado pelos professores que o utilizam, representa a concretização de um conceito de inclusão digital [Silveira e Casino 2011] e integração da tecnologia na escola, embasado em três pressupostos: (1) na mobilidade inerente aos notebooks, (2) na conectividade da Web e (3) na flexibilidade proporcionada por um conjunto de Sistema Operacional e aplicativos de código aberto.

Esta tripla especificidade da plataforma UCA, se refletiu, concomitantemente numa gama de vantagens para a produção midiática baseada em texto, imagem e áudio, a qual compensa, inclusive, a baixa capacidade do equipamento para a edição de vídeo digital.

O equipamento disponibilizado pela escola consistiu num lote de computadores modelo XO com dispositivo de captura de som digital integrado ao hardware e equipado com software livre para edição de áudio, o Audacity $1.3^{1}$. Cada participante contou com a possibilidade de usar um computador pessoal para o exercício de escrita de roteiro, gravação e edição de áudio.

\footnotetext{
${ }^{1}$ Ver http://sourceforge.audacity.net .
} 
Do ponto de vista estritamente técnico, verificamos que as especificações para a gravação de áudio em formato estéreo com resolução de 16 bits e amostragem de $48 \mathrm{kHz}$ equivalente ao padrão "wav" (não-comprimido) e mais o suporte ao formato "ogg" (comprimido, nativo do ambiente Linux/Unix), presentes no XO, são suficientes para garantir uma qualidade satisfatória nas produções realizadas.

\subsection{Da metodologia}

Do ponto de vista epistemológico, a formação aqui relatada se insere no bojo de um projeto de pesquisa, na modalidade pesquisa-ação [Barbier, 2004] em nível de pósdoutoramento, o qual se propõe, justamente, a subsidiar a sistematização de um referencial metodológico para o uso das linguagens e formatos midiáticos, com ênfase no letramento digital e midiático de crianças e jovens. Entendemos aqui por "letramento" a construção de saberes significativos que possibilitem ao aluno operar transformações sociais por meio da compreensão e o exercício de seu próprio papel enquanto cidadão. Na prática, o workshop aqui proposto se converte numa estratégia para o uso otimizado da plataforma XO, centrada no desenvolvimento compartilhado entre formador e participantes da metodologia no ambiente escolar.

O corpo docente envolvido na formação dividiu-se em dois grupos, sendo um de professores do $5^{\circ}$ ao $9^{\circ}$ ano e outro de professores do Ensino Fundamental I (do $1^{\circ}$ ao $4^{\circ}$ ano), sem a exigência de qualquer pré-requisito técnico ou pedagógico para iniciar o trabalho. Ambos os grupos dispunham de um encontro de formação semanal para o projeto específico de produção de narrativas em linguagem de rádio.

As atividades de formação vêm acontecendo semanalmente durante um dos horários de estudo coletivo garantido aos professores pela Secretaria Municipal de Educação. Cada um dos encontros tem duração pelo menos uma hora e trinta minutos, sendo que, aos professores participantes, se oferece ainda um contato de e-mail para esclarecimento de dúvidas e cumprimento de tarefas.

A concepção original foi a de se fazer três encontros temáticos de modo a oferecer uma formação inicial que conciliasse sensibilização, desenvolvimento instrumental contextualizado (nos recursos tecnológicos presentes no $\mathrm{XO}^{2}$ ) e desenvolvimento de habilidades comunicativas orais e textuais (em técnicas de roteirização e locução).

Dessa forma, os três temas sugeridos para cada um dos encontros são:

I. Da Narrativa Sugerida a Narrativa de Vida, no qual se introduz o conceito de narrativa com base no conhecimento de vida dos participantes e se apresenta a proposta de contar uma história significativa seguindo o modelo da comunicação radiofônica. Como tema gerador da narrativa, trabalhamos a partir de uma imagem e as diferentes interpretações que ela pode suscitar.

\footnotetext{
${ }^{2}$ Como por exemplo, o software open source para edição de áudio Audacity, utilizado neste projeto.
} 
II. Da Narrativa Oral a Narrativa Escrita, no qual uma determinada narrativa, criada ou escolhida pelos participantes, é fixada na forma de texto-base e, em seguida, adaptada no formato de roteiro radiofônico. O processo todo serve para exemplificar a diferença entre as formas escrita e oral do narrar. Começam aí, também, os exercícios de verbalização (leitura branca, leitura dramática) e testes de gravação que vão, aos poucos, familiarizando o participante com a produção em áudio.

III. Da Narrativa Verbal à Narrativa Midiática, no qual, partindo do material bruto das gravações e testes iniciais, se demonstram os recursos insuspeitadamente poderosos oferecidos pelo conjunto hardware-software do XO no tocante às possibilidades de tratamento de áudio. Além das operações básicas de importação e tratamento de arquivos, são introduzidos os conceitos de áudio, parâmetros sonoros, timeline e ambiência, além das competências relacionadas com a edição multipista.

\section{Considerações e resultados esperados}

Ainda que não possamos, nesse momento, falar em considerações e resultados finais, ao final dos três encontros desenvolvidos — e aproveitando o tempo transcorrido entre os mesmos para complementar as tarefas propostas - é possível produzir peças curtas com um grau razoável de acabamento, o que inclui elementos como sonoplastia e trilha sonora.

Além da possibilidade de autoria oferecida ao participante, a estratégia vivencial fornece a ele um modelo seguro que ele pode, posteriormente, exercitar em projetos de sua disciplina com seus próprios alunos.

Nossa hipótese de trabalho, frequentemente confirmada, é a de que a formação docente sai beneficiada quando se estabelece, de partida, que o workshop não se constitui numa formação técnica "agregada" ao trabalho docente: na verdade, trata-se do resgate dos saberes dos professores, os quais, nunca são considerados como tabula rasa em relação à mídia e ao uso das linguagens comunicacionais na sala de aula.

Um outro aspecto que se mostrou relevante foi o resgate histórico das Narrativas pessoais e comunitárias do grupo. No caso, sendo todos professores, quando colocados ante a escolha do objeto da narrativa, a maioria deles aderiu unanimemente à proposta de narrar às próprias histórias de professores que eles conheceram.

Como já mencionado, estes encontros de formação se caracterizam como um work in progress, mas o encaminhamento sugere alternativas bem interessantes na gestão compartilhada dos recursos do XO com os próprios educadores. 


\section{Referências}

Barbier, René. (2004) A Pesquisa-Ação. Brasília, Liber Livro.

Buckingham, David. (2003) Media Education. Cambridge (UK): Polity Press.

Consani, Marciel. (2007) Como usar o Rádio na Sala de Aula. São Paulo, Contexto.

Maia, Ivan F. (2011) No jardim dos letramentos: poéticas em rede e tomadas de consciência na cultura da convergência. Tese de doutorado em Multimeios. Universidade Estadual de Campinas, Campinas,. Disponível em: http://www.bibliotecadigital.unicamp.br/document/?code $=000840127 \&$ opt $=4$

Maia I. F. e Valente J. A. (Abril/2011) Os letramentos na cultura da convergência. In Revista e-curriculum (PUC-SP). Disponível em:

http://revistas.pucsp.br/index.php/curriculum/article/view/5642/3986, acesso em 15/07/2013.

Moore, Michael e Kearsley, Greg. (2007). Educação a Distância: uma visão integrada. São Paulo, Cengage Learning.

Silveira, Sérgio A.; Cassino, João (org.). (2003) Software Livre e Inclusão Digital. São Paulo: Conrad/ Editora do Brasil,.

Soares, Ismar. (2011). Educomunicação: Propostas para a reforma do Ensino Médio. São Paulo, Ed. Paulinas.

Valente, José A.; Martins, Maria Cecília. (2011) O Programa Um Computador Por Aluno e a formação de Professores das escolas vinculadas à Unicamp. Revista Geminis ano 2 - n. 1, p. 116 - 136. Disponível em:

http://www.revistageminis.ufscar.br/index.php/geminis/article/view/43/40. Acessado em: junho de 2012. 